\title{
Incorporating Powtoon as a Learning Activity into a Course on Technological Innovations as Didactic Resources for Pedagogy Programs
}

\author{
https://doi.org/10.3991/ijet.v12i06.7025 \\ Marcelo Humberto Rioseco Pais \\ Universidad Católica del Maule, Maule, Chile \\ mrioseco@ucm.cl \\ Fraño Paukner Nogués \\ Universidad Católica del Maule, Maule, Chile \\ fpaukner@ucm.cl \\ Bruno Ramírez Muñoz \\ Universidad Católica del Maule, Maule, Chile \\ bramirez@ucm.cl
}

\begin{abstract}
This paper describes the incorporation of the PowToon program as an activity for a course on Technological Innovations as Didactic Resources, in two pedagogy programs at Universidad Catolica del Maule (UCM) in Chile. This activity has been designed based on the 'learning by doing' paradigm, backed up by existing resources available in The Cloud. The students' perceptions about the use of the program were collected through the use a closedended/open-ended question survey. The data analysis was carried out by using a mixed methodology (qualitative/quantitative) and, in general terms, showed positive results on the use of PowToon, not only on the motivational aspect, but also regarding its contribution on learning new contents and developing ICTrelated abilities. However, opinions are still divided on the aspect of userfriendliness.
\end{abstract}

Keywords-PowToon, learning by doing, learning in the Cloud, ICT, pedagogy programs (undergraduate teacher training programs)

\section{Theoretical Framework}

\subsection{Constructivist learning, based on learning by doing}

According to its etymology, learning comes from the Latin apprehendere $(\mathrm{ad}=$ towards and prehendere=to perceive). Furthermore, Robbins (2004) defines learning as "any significant and relatively permanent change in a person's behavior, as a result of an experience." Through learning, abilities, skills, knowledge and values 
are modified due to experience, not due to biological or physiological factors, which depend entirely on the organisms' internal functions.

From a constructivist point of view, learning consists of creating meaning from experiences and, taking into account that from a single experience many meanings can be produced, it is impossible to achieve just one single and "correct" meaning. Knowledge is not something independent from the mind, so it cannot be understood as a realistic representation of the world, but as an interpretation of our own experiences. According to neuroscience, learning consists of changes in the synaptic connections which cause differences in thinking and behavior. Brain structures are modified by learning through new connections and Hebbian networks. Human beings create meanings, which are neither acquired nor obtained, from the real world. Thus, concepts evolve and transform themselves every time they are used. Reality is not something "objective" that students need to make an effort to know, but rather internal representations under a permanent transformation process. Comprehension cannot be depicted in just one single definition that can be recalled from memory, but can, however, be built upon real contexts through interaction. It is not about recovering intact information structures, but rather about students developing the means to create specific comprehension through a process of prior knowledge assembly. Therefore, it is necessary for knowledge to take place in a real environment and through activities related to the individual's learning experiences. This is called meaningful learning. Hence, through this type of learning, prior knowledge modifies the new knowledge as well as the experience, which, in turn, also determines and restructures the prior one. From this point of view, knowledge is not abstract, but is, however, linked to context and experience.

The teacher's role, under this approach, consists of guiding students towards the construction of their own learning as well as encouraging and facilitating collaboration with others, which will allow students to discover multiple perspectives on a particular issue or problem. After gaining more confidence and experience, students will eventually advance towards a cooperative learning phase in which discussion and dialogue are the fundamental tools for the intellectual growth of the students and the group they belong to.

Activities play a major under the constructivist perspective: knowledge is not constructed in abstract but in a real-world setting instead, where learners can modify their experience and skills "by doing". Meaningful learning is not senseless information, but a process of prior knowledge assembly or storage in order to generate adaptive responses to new situations.

However, the activities carried out by individuals are expressed in different ways and at different complexity levels. There are activities that challenge the intellect, others that challenge emotions and yet others that even challenge physical capacity. More precisely, it can be stated that they involve, to a greater or lesser extent, the individual's own intelligences, based on the theory of multiple intelligences by Howard Garner (1983): musical, bodily-kinesthetic, logical-mathematical, linguistic, spatial, interpersonal and intrapersonal intelligences. Of course, none of these intelligences work in isolation. For example, children who develop the ability to write mainly use their linguistic intelligence, but when they write, they can also use motor 
intelligence, which allows them to manipulate the keyboard or trace the words with a pencil. In this sense, activities do not only involve different forms of intelligence, but also different complexity levels: Understanding and solving second-grade equations require understanding first-degree equations and, prior to that, know how to do numerical reversibility operations. Something similar occurs when a gymnast or dancer performs a routine: Before performing he/she needs to learn how to coordinate many movements, do muscle work outs and improve flexibility.

There are activities that are simply related to the behavior that a person demonstrates through his/her capabilities; Others, however, show these capabilities through a tool, an instrument, an appliance or a prosthesis, widening the possibilities of transforming the world the individual is surrounded by. For example, with regards to material landscape transformation, the use of machines immensely increases performance capacity over a person. In mathematics and accounting operations, the use of spreadsheets allows extremely complex processes to be carried out under a very short period of time. In spatial thinking and graphic design, image processing applications and 2D and 3D figures are very useful in creating virtual elements and space. Currently, a myriad of activities is carried out by using digital tools that can expand people's capabilities to limits never before known in the history of mankind.

Nowadays there are computational tools to increase and substantially improve memory capacity or storage, calculation, verbal expression and communication. All these capabilities become evident through the interaction of humans and computers.

\subsection{Learning in the Cloud}

The Cloud is an "infinite" set of data available to thousands of users who can directly download and run the programs and the software applications through information servers (Google Maps, Gmail, Facebook, Tuenti or Flickr) distributed throughout the world. In "The Cloud" everything that a computer system can provide is offered as a service. Emails are read and stored remotely, like in Google Mail (gmail.com), Yahoo Mail (yahoo.com, yahoo.es), Microsoft Mail (live.con, hotmail.com), etc.; it is also possible to upload and download videos (youtube, vimeo, etc.), photographs (Flickr, Picasa, etc.), listen to any type of music (audio streaming, Spotify, etc.) or even manage a business. According to Huth and James Cebula (2011), Cloud computing allows web space and storage resources to be obtained, similarly to e-mails:

Cloud computing is a subscription-based service where you can obtain networked storage space and computer resources. One way to think of cloud computing is to consider your experience with email. Your email client, if it is Yahoo!, Gmail, Hotmail, and so on, takes care of housing all of the hardware and software necessary to support your personal email account (Huth y Cébula, 2011).

Cloud computing has had a decisive impact on the world of technology, which is obviously also generating economic and social change. Cloud services allow multiple businesses and users to share multi-tenant resources, and thus eliminating complex 
restrictions in the traditional computer environment and therefore optimizing space, time, energy and lowering costs as well.

In this sense, The Cloud is a virtual environment where users interact with information that is available to them from any Internet-connected device, such as computers, tablets, phones, smart watches, etc., with hardware features that are increasingly more and more common. Furthermore, this phenomenon is about tools and resources, publically available, which offer the possibility of extending an individual's cognitive ability and, therefore, being able to expand the scope and intervention of education in terms of student learning. Nowadays, the Cloud is likely to become an environment through which education can develop any of the multiple intelligences identified and described by Garner.

\subsection{Learning activity using PowToon}

PowToon is a tool whose operation is similar to Power Point, Impress, or even Prezi. It uses slides to which text and images can be added to, but it also allows animation and the incorporation of sound or music, available in the same application or through an external source. The result is a product that mixes the look or the appearance of a PowerPoint Presentation with a comic book.

These online visual presentations are a fast and eye-catching way to deliver information to diverse audiences within a very short time period. Some of the general advantages offered by the presentations are:

- They allow individuals to display or present any topic of interest and be able to share it with others

- They immediately attract the viewer if the presentation is well designed.

- They require students (when assigned tasks connected to the presentations) to read and synthesize information to later be able to present it.

- They achieve greater comprehension of the information being shown and make it easier to remember.

- They integrate different types of formats and media, increasing the integration capabilities of the visual, auditory and motion resources.

- Currently, most of these tools, in their basic version, are free of charge or are offered at a very low cost.

- These resources are generally compatible with several operating systems.

PowToon was founded in January 2012, and in August of that same year the beta version was released. PowToon uses Adobe Flex technology that generates an XML file. This file can be executed in the PowToon online visor or exported to YouTube.3. It is a program used for designing presentations in The Cloud, and offers a free version for teaching. Like most of the programs that run in The Cloud, it is necessary to register before being able to start working with it. Once registered, it is necessary to access an editing screen and submit the desired slides or use one of the predesigned templates. Each slide, which functions as a kind of canvas, can be edited by adding text, images and animation. The presentations developed in PowToon can be stored in 
a traditional format, which allows the slides to move one by one, or be exported to Youtube as a video file where there is a special channel for PowToon. The videos made by using free accounts include the PowToon watermark.

The following learning activity using PowToon was developed in two undergraduate pedagogy programs (The Elementary School Pedagogy Program and the English Pedagogy Program) within the context of the course: Technological Innovations as Didactic Resources (TIDR), carried out at Universidad Catolica del Maule (UCM), Chile.

This course, taught in these two programs, aims to develop the necessary competences for getting to know and for using the computing resources, as well as carry out various teaching and administrative activities at the university. The course is about the role of ICTs in today's society, based on knowledge access and knowledge production, taking into consideration the contributions from the research in areas such as Cognitive Science, Theories of Learning and Neuroscience. It is stated in the literature that the use of digital technologies promotes learners' skill and ability development.

The basic premise adopted by the TIDR course to design the teaching-learning process is "learning by doing." Even the conceptual knowledge acquired by a student is related to what is done with the concepts: linking them together, applying them in specific situations, translating them into different types of language, etc. Based on this perspective, the course aims to subject the logic of content learning to one that is activity-based. This is carried out by thinking about the different levels of complexity and the interrelationship between one activity and another.

The activity described below is taken from the lesson plan called "Knowledge Society," which requires students to develop a proposal for teaching sex education to high school students within the context of a society determined by the use of Internet and social networks. In order to carry this out, they are instructed to make a video, using PowToon, where they are to incorporate problem identification, data definition, and the impact or the changes expected through this proposal. The video, required to last four to five minutes, is an important evaluated assignment within the course.

\section{Methodological Framework}

\subsection{Population and sample}

All the undergraduate students taking the TIDR course from the Elementary Pedagogy Program and the English Pedagogy program at UCM were invited to fill out the survey. A total of 47 students out of 61 participated.

24 students $(51 \%)$ were enrolled in the Elementary Pedagogy Program and 23 (49\%) were part of the English Pedagogy program. In terms of gender, 37 subjects were female $(79 \%)$ and 10 were male $(21 \%)$. In terms of age, 31 of them are between 19 and 22 years old (66\%), and 13 are between 23 and $26(28 \%)$. Only one person is younger than $18(2 \%)$ and two older than $27(4 \%)$. 


\subsection{Students' perception about the activity using PowToon}

A survey was applied after carrying out an activity using PowToon, in order to gather information about students' perception. The survey included two questions: How did you like working with PowToon? What can be highlighted, positively or negatively, about the use of PowToon in developing activities for this course?

The first one was a closed-ended question which had four items using a doubleentry chart. The respondents were required to assess the extent of their agreement with the item. A Likert scale was used to measure every item in order to determine the student's degree of agreement:

5. Fully agree with the statement.

4. Partially agree with the statement.

3. Neither agree nor disagree with the statement.

2. Partially disagree with the statement.

1. Fully disagree with the statement.

The second question intended to establish the participants' point of view by establishing a minimum amount of restriction in their answers. The question was designed by taking into account the objectives of the study as well as the theoretical framework.

It is worth mentioning that the students participated voluntarily and anonymously. They were previously explained the research purpose and asked to sign a consent form to analyze their answers and, eventually, publish them in an article.

The methodology selected to carry out the analysis was a mixed methodology, with a qualitative emphasis; the answers to the first question were processed through quantitative techniques and the data collected from the second question were analyzed and interpreted through qualitative techniques.

\section{$3 \quad$ Results}

\subsection{Quantitative results}

The students' answers were analyzed according to the frequency in the degree of agreement manifested in each item. Then, they were analyzed according to demographic variables (Students' gender, major, age).

Frequency of answers by item: In general, the features of the program that showed the highest degree of agreement are related to the fact that PowToon allows the use of new abilities ( $72 \%$ fully agrees and $25,5 \%$ agrees), suitable to learn new contents $(57,4 \%$ fully agrees and $29,8 \%$ agrees), and motivating (51,1\% fully agrees and $38,8 \%$ agrees). Barely $14,9 \%$ fully agrees that working with PowToon is easy, while $34 \%$ agrees with this statement. On the contrary, more than half of the students $(51,1 \%)$ has a neutral view, $25,5 \%$ disagrees, $17 \%$ fully disagrees with the statement that working with the program is easy. In the rest of the items, answers in agreement or that are neutral are quite few: $12,8 \%$ neither agrees nor disagrees with the idea that PowToon is suitable to learn new contents, $6,4 \%$ agrees that it is motivating and $2,1 \%$ agrees that it is effective in the use of new abilities; $4,3 \%$ agrees with the statement 
that PowToon is motivating, while no student disagrees that it is suitable to learn new contents as well as to use new abilities; finally, no student fully disagrees that PowToon is motivating and suitable to learn new contents and useful in developing new skills.

Table 1. Frequency of answers by item

\begin{tabular}{|l|c|c|c|c|c|c|c|c|c|c|}
\hline \multirow{2}{*}{ ITEM } & \multicolumn{2}{|c|}{5} & \multicolumn{2}{c|}{$\mathbf{4}$} & \multicolumn{2}{c|}{$\mathbf{3}$} & \multicolumn{2}{|c|}{$\mathbf{2}$} & \multicolumn{2}{|c|}{$\mathbf{1}$} \\
\cline { 2 - 11 } & $\boldsymbol{f}$ & $\mathbf{\%}$ & $\boldsymbol{f}$ & $\mathbf{\%}$ & $\boldsymbol{f}$ & $\mathbf{\%}$ & $\boldsymbol{f}$ & $\mathbf{\%}$ & $\boldsymbol{f}$ & $\boldsymbol{\%}$ \\
\hline $\begin{array}{l}\text { Working with } \\
\text { PowToon is moti- } \\
\text { vating }\end{array}$ & 24 & $51,1 \%$ & 18 & $38,3 \%$ & 3 & $6,4 \%$ & 2 & $4,3 \%$ & 0 & $0,0 \%$ \\
\hline $\begin{array}{l}\text { Working with } \\
\text { PowToon is easy }\end{array}$ & 7 & $14,9 \%$ & 16 & $34,0 \%$ & 12 & $25,5 \%$ & 8 & $17,0 \%$ & 4 & $8,5 \%$ \\
\hline $\begin{array}{l}\text { Working with } \\
\text { PowToon is suita- } \\
\text { ble to learn new } \\
\text { contents }\end{array}$ & 27 & $57,4 \%$ & 14 & $29,8 \%$ & 6 & $12,8 \%$ & 0 & $0,0 \%$ & 0 & $0,0 \%$ \\
\hline $\begin{array}{l}\text { Working with } \\
\text { PowToon is useful } \\
\text { to develop new } \\
\text { skills }\end{array}$ & 34 & $72,3 \%$ & 12 & $25,5 \%$ & 1 & $2,1 \%$ & 0 & $0,0 \%$ & 0 & $0,0 \%$ \\
\hline
\end{tabular}

Answers by gender: According to students' ' $t$ ", the analysis shows that there are statistically significant differences regarding gender in the first two items: women consider, to a greater extent, that working with PowToon is motivating $(\mathrm{t}(45)=.724$, $\mathrm{p}=0.19<0.05)$ and easy $(\mathrm{t}(45)=.594, \mathrm{p}=.019<0.05)$. Hence, this indicates that being male or female is an incidental variable in the opinions that students had in those two items. Furthermore, in the item related to the program being suitable for learning new contents and useful in developing new abilities, no statistically significant differences are shown.

Answers by program: According to " $t$ ", the analysis shows that there are only statistically significant differences regarding students' major in the item that refers to PowToon being useful in developing new abilities. This difference is favorable to the group of students belonging to the Elementary School Pedagogy program ( $t(45)=$ $.1860, \mathrm{p}=.016<0.05)$.

Answers by age: In order to know the relation between the students' age (quantitative variable) and their answers about using PowToon, a parametric analysis using the Pearson's Correlation Test was done. According to this analysis, there is NO significant correlation (Hernández, 2010) between the participants' age and any of the items in the survey. This lack of significant correlation can be observed in the following chart.

\subsection{Qualitative results}

One of the open-ended questions asked in the survey was: What is the most important aspect to highlight, either positively or negatively, about the use of PowToon 
for the purpose of the course? This question was answered by all the pedagogy students (47) that participated in the study.

The data were processed using Atlas-ti 6.2, taking into account some of the features and purposes that define qualitative analysis, according to Hernández (2010): To provide structure to the data by organizing, interpreting and evaluating the units, the categories, the topics and the patterns; to make sense out of the data; to explain the phenomenon. The analysis procedure used was Grounded Theory (Strauss \& Corbin, 1990) where, firstly, units of analysis were identified; then they were coded at first level by the assignment of codes and categories. Then, coding of second level categories took place, in which the definitions and conceptualizations were integrated. Finally, explanations from the collected and processed data were established through both previous levels.

The following codes represent the concepts indicated in the table.

Table 2. Code meaning

\begin{tabular}{|c|l|}
\hline Code & \multicolumn{1}{|c|}{ Signification } \\
\hline F & Family \\
\hline CF & Code family \\
\hline U & Use \\
\hline R & Requirement \\
\hline FU & Usefulness \\
\hline AN & Negative aspects \\
\hline AP & Positive aspects \\
\hline EX & Perception \\
\hline
\end{tabular}

PowToon program usefulness: The first PowToon related topic identified in the answers given by the pedagogy students is the usefulness of the program in the educational field. It is a useful support tool, within the teaching-learning process, for the elaboration and expression of contents and for the creation of audiovisual material, which is shown through the use of animation and videos to make didactic material.

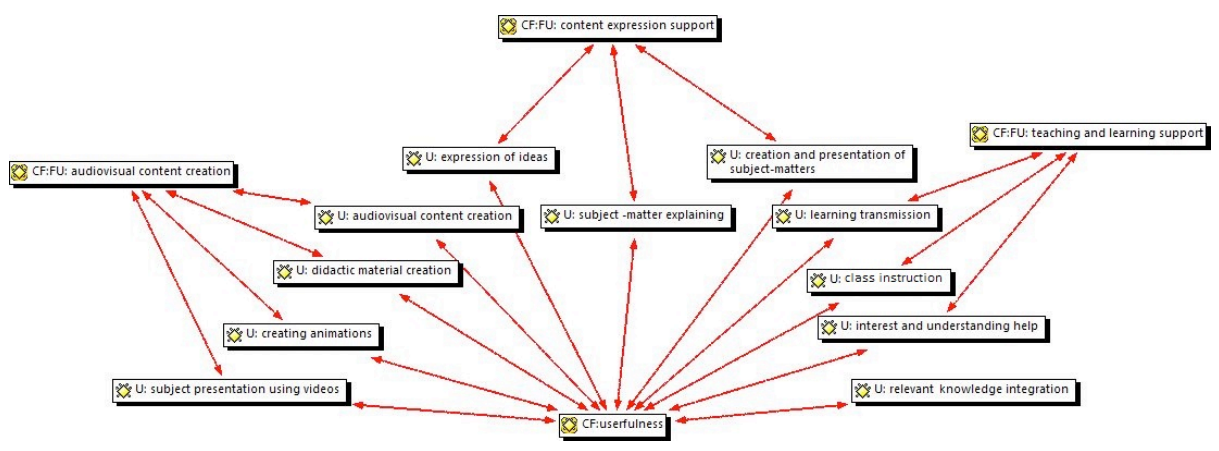

Fig. 1. PowToon usefulness - general representation 
In relation to the usefulness of the program, it is possible to confirm that its use can be gratifying, despite that the fact that it requires time and dedication, as well as skill development.

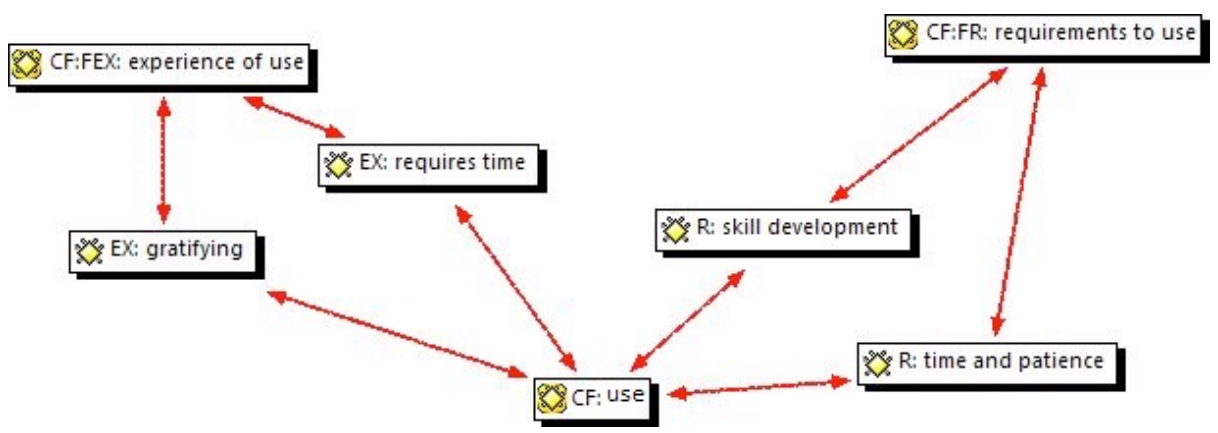

Fig. 2. Use of PowToon

Positive aspects: Some of the positive aspects related to the use of PowToon mentioned by the students has to do with the aid or support it provides during the teaching and learning process, not only for the teacher but for the student as well, by challenging and stimulating creativity, familiarizing them with the use of ICTs and helping in the creation of didactic material.

Furthermore, it is mentioned that the program is suitable to be used in the educational field, mainly because it has several tools and various effects incorporated that make it, among other things, motivating, didactic, dynamic and attractive for children.

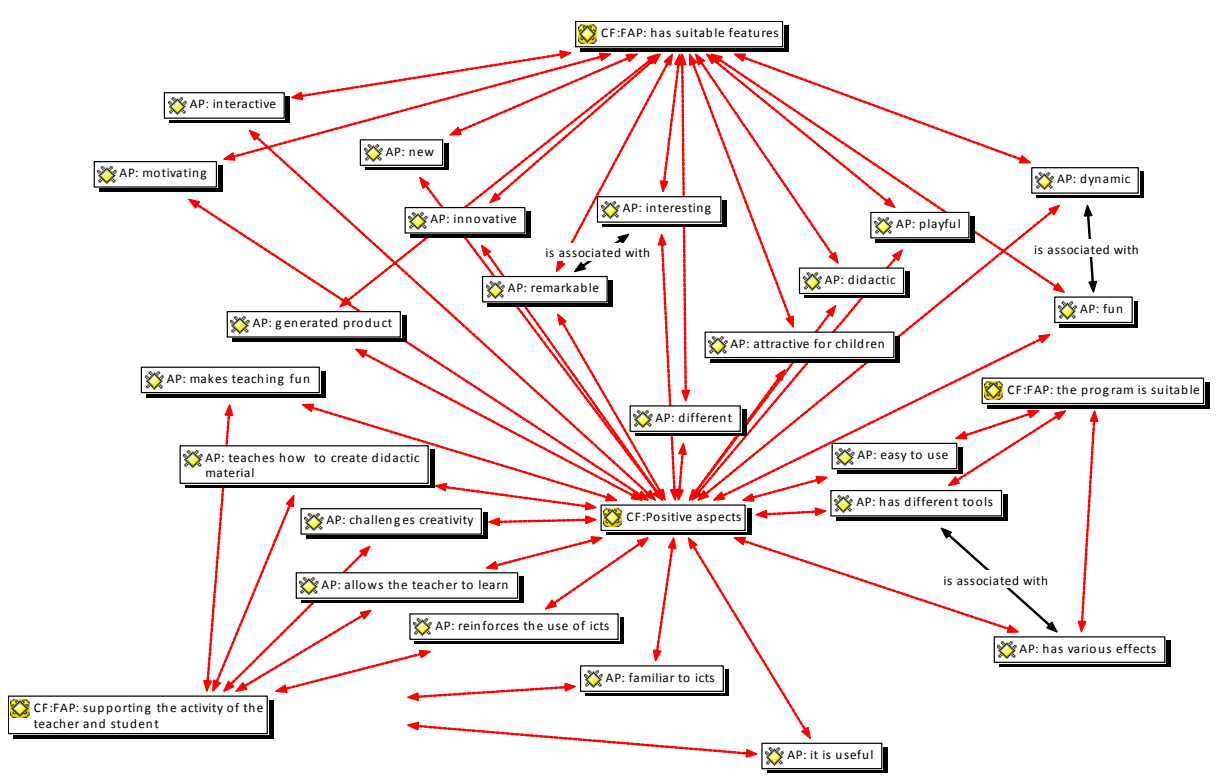

Fig. 3. Positive aspects of PowToon 
Negative aspects: The pedagogy students who participated in the study mostly agreed that the negative side of using PowToon is related to three main aspects: a) the difficulty for Spanish speakers to use it because it just has an English interface. This is mainly a problem for children because they cannot speak English. b) The second aspect has to do with the program having a time line which requires that all the elements be programmed and assembled together. This feature, however, is also mentioned as a positive aspect by other students who see it as being related to the dynamic way in which information is presented in PowToon. c) Finally, another aspect mentioned as negative has to do with the restrictions on the use of the program without having a paid account: it is impossible to save what has been created in the computer, and is only made available in the web. Moreover, there are many resources that can be seen but are unavailable to be used with a free account.

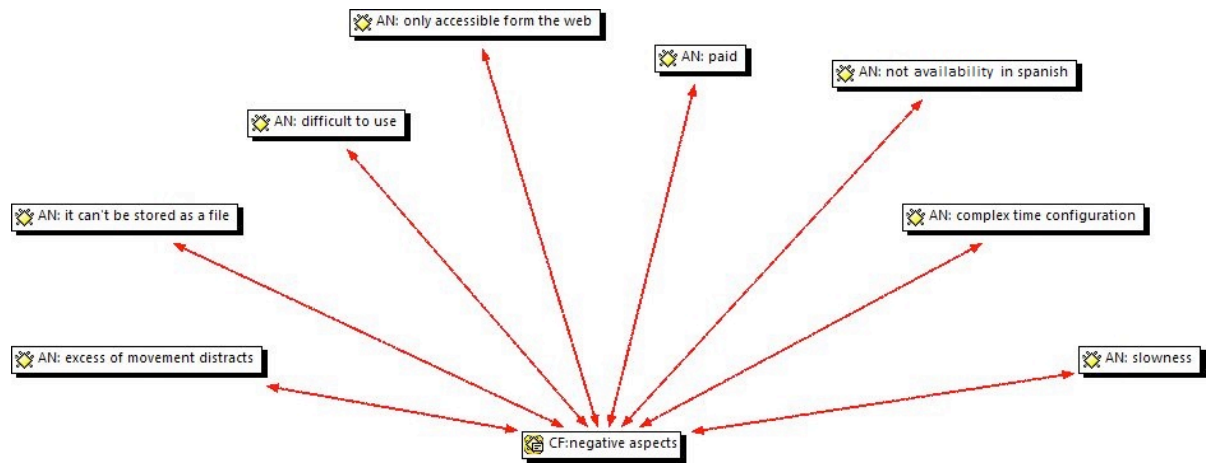

Fig. 4. Negative aspects of PowToon

\section{Conclusions}

Students have a positive opinion about the use of PowToon in the development of learning activities related to undergraduate teacher education in the TIDR course, especially in the unit about different aspects of the Knowledge Society. In general terms, a high percentage of mostly female students consider PowToon to be a motivating tool used to create interactive materials through animation and videos.

Regarding the usefulness of PowToon in supporting the teaching and learning process, the students think that the program is suitable for the learning of contents and for skill development, as well. With regards to this, there is an overall good opinion about it, especially among elementary school pedagogy students. Another element worth mentioning is the possibility that the application offers to express or transmit information through the creation of audiovisual material thanks to the great amount of tools and effects PowToon has to offer.

Based on this point of view, the authors of this research paper agree with Tracy Weber (2014) who states that it is possible to use PowToon in any type of class:

PowToon can be used in any class. It could be employed in an English class to demonstrate knowledge of Romeo and Juliet from a student's perspective; in an Agri- 
culture class to demonstrate how to fix an engine or properly fertilize crops/plants; and even in an industrial arts class by demonstrating welding techniques.

Also, the data obtained in this research are similar to results obtained in a study conducted by Marta Pinto (2014), from the Católica Portuguesa University, in Portugal. As part of a curricular unit on supervising teachers within the ICT discipline, students had to write their own digital stories using web 2.0 tools (GoAnimate, Movie Maker and PowToon). According to the data gathered, among 54 seventh grade students, $75,9 \%$ of them thought that the use of web 2.0 tools made content learning easier, strengthened meaningful learning and developed general skills. $81 \%$ of these students thought that the activity was challenging and stimulated active, collaborative and meaningful learning, arousing their interest and encouraging commitment with one's own learning.

Finally, regarding user-friendliness, opinions are divided. Some students think PowToon is easy to use, while others think it is complicated. The factors that make using the program difficult have to do with, mostly, menus and commands, which are presented to students in a foreign language. Despite the fact that many of the elements that allow a determined program to be managed are common to many applications, regardless of the interface language, the fact that PowToon just comes in English is seen as an obstacle hard to overcome by students. This difficulty is made worse by the fact that they are very accustomed to using PowerPoint. Hence, PowToon is seen as an application that structures itself in a very unusual way, where elements are managed in a different way from that of PowerPoint. Furthermore, some students see the restrictions imposed on free accounts as a real problem since this means that many tools and resources can only be accessible through a paid subscription. Finally, the fact that students cannot save what they have created as a downloadable file is seen as quite a negative aspect.

\section{$5 \quad$ References}

[1] Garner, H. (1983). Frames of Mind. The Theory of Multiple Intelligences. Nueva York: Basic Books. Graw-Hill Interamericana.

[2] Gutiérrez, I., Castañeda, L. y Serrano, J.L. (2013). Más allá de la Flipped Classroom: “dar la vuelta a la clase" con materiales creados por los alumnos. II Congreso Internacional Educación Mediática y Competencia Digital, Barcelona, España.

[3] Hernández, R., Fernández, Ca., Baptista, P. (2010). Metodología de la Investigación. México: Mc. Huth, A. \& Cebula, J. (2011). The Basics of Cloud Computing. EEUU: Carnegie Mellon University.

[4] INTECO-CERT (2011). Riesgos y Amenazas en Cloud Computing. España: Ministerio de Industria, Turismo y Comercio.

[5] Pinto, M. (2014). A utilização da narrativa digital no auxílio da aprendizagem das TIC: um estudo de caso com alunos do 7. ${ }^{\circ}$ ano de escolaridade. Dissertações de Mestrado / Master Dissertations. Universidades Católica Portuguesa.

[6] Robbins, P. (2004). Comportamiento Organizacional (pp 43 y 44). México: Pearson Educación.

[7] Strauss, A. L., \& Corbin, J. M. (1990). Basics of qualitative research: Grounded theory procedures and techniques. Newbury Park, Calif: Sage Publications. 
Paper-Incorporating Powtoon as a Learning Activity into a Course on Technological Innovations as..

[8] Weber, T. (2014). Tools for Teachers and Students. Techniques: Connecting Education \& Careers, 89(3), 8 .

\section{Authors}

Dr. Marcelo Humberto Rioseco Pais (primary author) is with the Facultad de Educación - Departamento de Fundamentos de la Educación, Universidad Católica del Maule, Maule, Chile (rioseco.marcelo@gmail.com, +56942202315)

Dr. Fraño Paukner Nogués is with the Facultad de Educación - Departamento de Fundamentos de la Educación, Universidad Católica del Maule, Maule, Chile (fpaukner@ucm.cl, +56712203453).

Professor Bruno Ramírez Muñoz is with the Facultad de Educación Departamento de Idioma, Universidad Católica del Maule, Maule, Chile (bramirez@ucm.cl,+56712203701).

Article submitted 18 April 2017. Published as resubmitted by the authors 27 May 2017. 